\title{
Cognitive Mapping: A Process to Support Strategic Planning in an Academic Department
}

\author{
ROY D. JOHNSON AND ASTRID LIPP \\ University of Pretoria, Department of Informatics, IT building 5-95, Pretoria 0002, South Africa; \\ Department of Computer Information Systems, Robinson College of Business, Georgia State University, 35 \\ Broad Street,Atlanta, GA 30303
}

\begin{abstract}
Cognitive mapping has been used to support strategic planning in business. However, the process has seldom been utilized to support strategic planning in nonprofit public organizations, where many reporting lines are less clear. This paper describes how the cognitive mapping process was designed and implemented to help a large academic department identify and merge the individual goals of faculty members as a first step in creating a strategic plan. Each map was created using the Decision Explorer ${ }^{\mathrm{TM}}$ software during individual interviews, as opposed to using paper and pencil. An action case approach was used to plan and evaluate individual mapping sessions. Eliciting individual cognitive maps led to greater engagement by faculty in the strategic planning process. Nearly all of the participating faculty members believed that the cognitive mapping process was helpful and insightful and the resulting map was accurate and complete.
\end{abstract}

\section{Introduction}

In the past two decades, the environment of public nonprofit organizations and communities has changed dramatically. Such changes force leaders and managers of public agencies and nonprofit organizations to address difficult challenges. "Organizations that want to survive and prosper must respond to these changes (p. 3)” by thinking and acting strategically as never before (Bryson 1995). During the same time period, the Computer Information Systems (CIS) Department at a large public university in the southeastern United States described in this paper had grown rapidly in terms of the number of faculty and students, and it had a new department chair. The number of faculty in the department had increased to 33; 25 were full-time and eight were part-time faculty members. Among the 25 full-time faculty, six were non-tenure track faculty (two instructors and four assistant professors), seven tenure track assistant professors, five associate professors, and seven full professors including four endowed chairs whose primary focus was research. Faculty interests ranged from highly technical (e.g., wireless networks) to highly managerial (e.g., information systems management). Student enrollment reached an all-time high of nearly 1,600 undergraduate students, over 500 Master's-level students, and more than 25 doctoral students in the department. The department appeared to be facing "a real turning point in its history - a point that might lead to success or deterioration (Bryson 1995: p. 235).” This created a compelling 
need to update its 10-year-old strategic plan, in order for the department to "survive and prosper” (Bryson 1995).

The new department chair held a departmental faculty retreat the week before classes started to develop a mission statement and strategic plan. During the retreat, faculty identified many issues facing the CIS department, including a lack of resources, trust, openness, and equity in salary, teaching, and service responsibilities, as well as dissatisfaction with the annual review process. Although faculty were able to formulate an agreed-upon mission statement at the end of the retreat, the strategic planning effort was not complete. With such a large academic department and a diverse faculty, it was difficult to get enough detailed input from individual faculty members during faculty meetings, retreats, or through e-mail to generate a new departmental strategic plan. Additionally, the department chair had limited resources. Hiring a consultant to facilitate the process was deemed to be out of the question.

Under such circumstances, it was important to select an appropriate strategic planning process that could be carried out relatively easily and involved as many stakeholders as possible because strategic planning should start where "people who might be involved in or affected by the process currently are (Bryson 1995 p. 234).” Although brainstorming and the nominal group technique can be used to support idea generation and sharing, they do not support identifying relationships between the ideas in order to continue the discussion. Other techniques, such as the snow card technique and "mind mapping” offer structure to brainstormed ideas by categorizing the ideas into logical, priority, or chronological order. These techniques, however, do not further clarify the relationships between ideas within or across categories (Bryson et al. 1995). The "oval mapping process" discussed by Bryson et al. (1995) and refined by other researchers (Ackermann and Eden 2004; Bryson et al. 2004; Eden and Ackermann 1998, 2001a,b) represents these relationships. The resulting map is later captured digitally using Decision Explorer $^{\mathrm{TM}}$ to show cause-effect or influencing relationships. Such action-outcome relationships identified during the mapping process help the people involved to "figure out what they can do about an area of concern (Bryson et al. 1995; p. 260).” Additionally, the mapping process is easy to understand and use. Mapping can enhance reasoning ability, improve dialogue, manage complexity, and build teamwork within the group (Bryson 1995). Those important benefits, along with the need to select a mapping technique that is low in difficulty and high in task engagement (Hodgkinson et al. 2004), justify the use of the mapping process in the CIS department's strategic planning process.

Although the mapping process is easy to use and identifies complex relationships relatively quickly, it can only be used with groups of up to 12 members or with individuals (Bryson et al. 1995). Because the department described in this paper had33faculty members, having everyone participate in a single mapping session was not feasible. It was apparent that the most appropriate methodology for developing a departmental strategic plan would involve scheduling mapping sessions with individual faculty members and congregating the individual maps into a collective structure (Bougon 1992).

This paper describes how the use of cognitive mapping to create individual maps, which are later congregated into a composite map, can lead to faculty engagement in the strategic planning process. As a result of faculty participation, the department chair anticipated that an improved strategic plan would result, and faculty commitment to the plan would be enhanced. 
Discussion of participant reactions to the use of the cognitive mapping process will be insightful to others charged with initiating the discussion of complex issues in large organizational groups. Others may find it convenient to create a cognitive map directly in

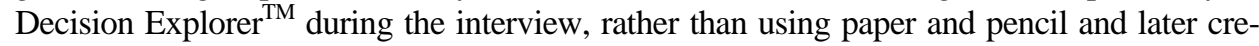
ating a digital version of the map. The resulting maps will be of interest to CIS departments and other professional organizations in which reporting lines are less clear than they are in corporations or government organizations (Power 1988).

This paper is organized in the following manner: a review of literature, the research methodology, results, discussion, and conclusion. Examples of cognitive maps will also be presented.

\section{Review of Literature}

According to Mosvick and Nelson (1987), 50 percent of time spent in meetings is wasted because meetings are poorly planned and clear goals are not identified. Research has also revealed the importance of employee participation in the strategic decision making process and the organization's success (Bryson 1995; Glew et al. 1995; Kim and Mauborgne 1998; Thompson 2000). As a result, multiple streams of research have explored how to make strategy formulation more effective and efficient through the use of collaborative technology to support face-to-face meetings (Bryson 1995; Dennis et al. 1997; Eden and Ackermann 1998). Eden and Ackermann (1998) discuss how cognitive mapping can be used to capture an individual's or group's thoughts during a session while participants have a chance to talk and think out loud. Participants in groups of more than 12 members "can be lost in the crowd and feel they are not part of the group (Bryson 1995; p. 258).” Additionally, a map created as a result of a group effort cannot completely represent the thinking of the individuals who participated in its creation (Eden and Ackermann 1998) as group mapping sessions do not allow anonymity, and every participant would not have time to contribute (Lipp and Carver 2000).

In contrast, mapping sessions with individuals offer relative anonymity and therefore create "an environment where the interviewee is able to discuss the problem without fear of direct recrimination (Eden and Ackermann 1998: p. 298).” Not only does mapping of individuals allow the facilitator to focus completely on each individual's views, but it enables the interviewee to reflect on his or her views, which "defuses potential dysfunctional confrontation and helps to avoid group-thinking (p. 299).” The individual whose thoughts are represented in a cognitive map can focus entirely on formulating and expressing thoughts, while a facilitator enters responses and asks questions to prompt for information and to clarify the concepts to be represented (Eden and Ackermann 1998). Additionally, cognitive mapping and repertory grids can be used to elicit an informant's construct system (Brown 1992).

Maps created through individual interviews can be congregated to create composite maps using the same techniques used to create individual maps. A facilitator must examine individual maps to identify substantially identical concepts (i.e., similar wording, same context but different maps, or both), which are then merged in the composite map by combining the wording used in individual maps. Incorporating the wording of multiple 
individuals gives each person a sense of ownership of the map. Concepts that only occur in one map are added to the composite map, which is called an "aggregated map" (Eden and Ackermann 1998: p. 210).

Cognitive mapping techniques have been applied in many settings and have been used to understand high-risk problems, such as what went wrong in the building of the Eurotunnel (Ackermann et al. 1997), as well as in less high-stakes problem solving, such as developing a United Kingdom take-home drink retailing strategy (Warren 1995). Researchers have also used cognitive mapping techniques to assess students' learning by having students create flowcharts to represent their mental models (Alavi et al. 2002), to develop guidelines for educators and trainers by creating composite cognitive maps based on the difficulties that students had in learning and using Object Oriented techniques (Sheetz et al. 1997: Sheetz et al. 1994), and to collect data for research (Narayanan and Armstrong 2005). Other applications of cognitive mapping include using congregate cognitive maps to represent social systems in which individuals' perceptions of the system are mostly idiosyncratic and not shared (Bougon 1992) and using comparative causal mapping to model actual systems and people's understanding of systems (Laukkanen 1998). Detailed descriptions of cognitive mapping techniques are offered by Ackermann and Eden (2004), Bougon (1992), Bryson et al. (2004), Eden (2004), Eden and Ackermann (1998, 2001a,b), and Laukkanen (1998). Huff (1990), Nelson et al. (2000), as well as Narayanan and Armstrong (2005) discuss the range of mapping techniques available and how they have been used.

Morton et al. (2003) distinguish between model-driven research (which focuses on the decision model) and technology-driven research (which focuses on the computer system used). They argue that the objective of model-driven research in group decision support is to offer a problem consultation service. The model-driven approach is therefore appropriate for a project whose purpose is both to help collect research data and create a strategic plan. Morton et al. (2003) also argue that a synergy between the two traditions is appropriate. However, no researchers have actually applied the combination of those two approaches to the strategic planning process in an academic department. This project represents such a synergy. The cognitive mapping technique was used to capture individual faculty members' perceptions of success factors so that a strategic plan (the model) for the department could be formulated through the use of Decision Explorer ${ }^{\mathrm{TM}}$ (the technology).

This paper represents a contribution to the body of knowledge for cognitive mapping as well as strategy formulation in professional organizations by offering an action case that shows how the use of individual interviews and cognitive mapping with Decision Explorer ${ }^{\mathrm{TM}}$ (rather than the traditional paper and pencil) during interviews can increase engagement of faculty in the strategic management process. The paper's contribution also includes composite maps containing success factors for faculty of computer information systems.

\section{Methodology}

An action case approach was used to examine causal relationships that contribute to the effectiveness of individual CIS faculty and the department. According to Braa and Vidgen (1999), an action case is a hybrid of action research (focused on organizational change) and 
a soft case (focused on understanding an organization at a particular time, but not effecting change).

In [an] action case the scope of the investigation is restricted in order that a small to medium-scale intervention can be achieved in a rich local context. ... The research question should be sufficiently focused such that the effects of the change can be studied. Lower levels of participation from the organization than generally needed for action research can be accommodated. But, despite these constraints, there will still be an orientation toward building the future through purposeful change (p. 40).

Figure 1 shows the research framework proposed by Braa and Vidgen (1999) and how an action case differs from action research and a soft case.

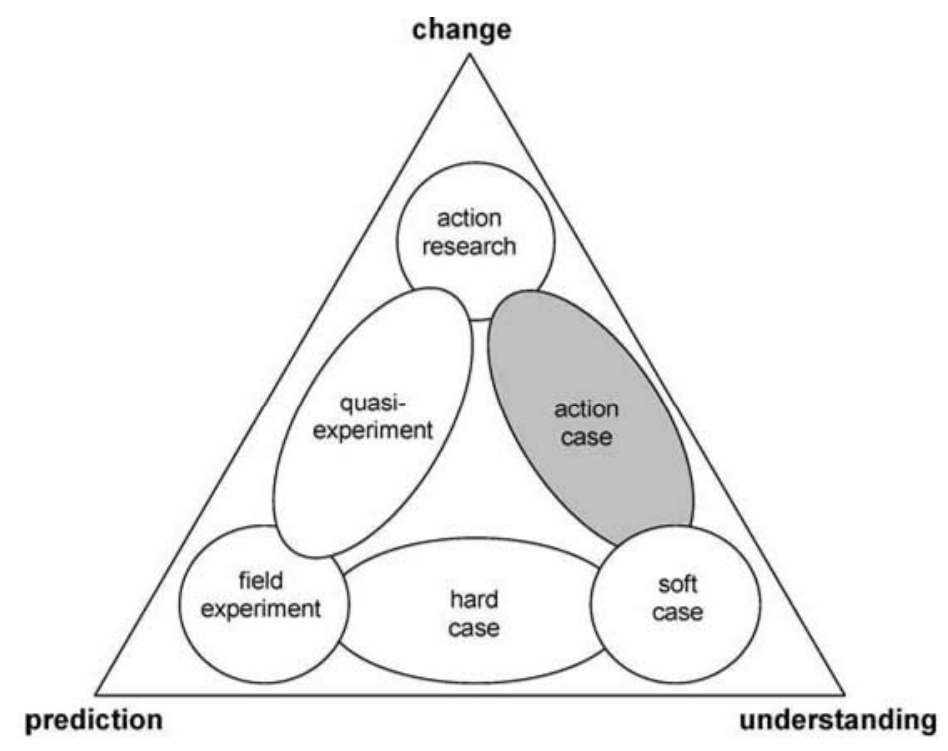

Figure 1. A research framework proposed by Braa and Vidgen (1999).

Braa and Vidgen (1999) explain that formal action research methodologies involve "intended, large-scale change" that is planned and implemented by the researcher. Formal action research methodologies require that the researcher complete all phases in an intervention process. Researchers have proposed different intervention processes, such as Susman's (1983) five phases of “diagnosing; action planning; action taking; evaluating; and specifying learning (Braa and Vidgen 1999; p. 30)” and Checkland's (1991) seven stage process. Regardless of which action research approach is used, a researcher plans the intervention, evaluates its effectiveness, and makes adjustments. Researchers using the case study method observe an organization for a limited period of time and present what they observed. They do not plan or implement any actions or interventions. Any change that occurs in an organization as a result of the case study researcher's presence and observations 
is unintentional. The action case approach is a hybrid of action research and participatory action research because the researcher intends to effect "small to medium scale" change (Braa and Vidgen 1999; p. 43). In this study, the authors' intended small-scale change involved helping faculty articulate goals, identify impediments to reaching goals, and determine how the impediments should be addressed.

This project involved designing, using, and evaluating a process for creating a departmental strategic plan for the CIS Department. In this case, the "intervention" planned and executed by the researchers gave faculty members a formal process to provide detailed input that was used as the basis for discussions leading to the formulation of a strategic plan. Based on the unique situation of the CIS department described earlier, interviews of individual faculty members were used to initiate the first step in the process of developing a departmental strategic plan. Decision Explorer ${ }^{\mathrm{TM}}$ (Decision Explorer ${ }^{\mathrm{TM}}$ Reference Manual 2000; Decision Explorer ${ }^{\mathrm{TM}}$ User's Guide 1997) was used in the cognitive mapping sessions. Various alternative mapping techniques (mind mapping and concept mapping) and mapping products (Mind Manager ${ }^{\mathrm{TM}}$, Visi Map ${ }^{\mathrm{TM}}$, Inspiration ${ }^{\mathrm{TM}}$ ) would have satisfied some, but not all of the requirements for representing the thinking of faculty members: (1) a diagrammatic rather than a linear approach, (2) concepts consisting of verb phrases, rather than individual words or pictures, (3) a network, rather than a tree structure (more than one main concept per map), and (4) links to represent causal relationships among concepts.

Facilitators set the frame for every interview by repeating the same three open-ended questions which were e-mailed to all faculty by the department chair before the cognitive mapping sessions were scheduled:

1. What are your professional goals?

2. What do you think the department's goals should be?

3. Where is the overlap between the two sets of goals?

Although the department chair's charge focused on goals, the focus during mapping sessions was on issues that faculty members felt needed to be addressed as well as possible strategies for addressing the issues. The authors produced a composite map from the individual maps and were prepared to serve as facilitators during a retreat at which the composite map would be validated and completed, to produce a strategic plan. This article focuses on the individual mapping sessions, which represented the first stage of the department's strategic planning process.

All subsequent questions asked represented follow-up questions about the topics mentioned by the faculty member being interviewed. Having a physical representation of the concepts and the causal links elicited during the interview assisted the facilitator and the faculty member not only in identifying and correcting the information displayed but also in identifying missing information.

Since an action case method was used, there was no control group, and the faculty members who participated in mapping sessions did so voluntarily. As a result, no hypothesis testing was conducted. Descriptive statistics are reported for questionnaire data. The following research questions were explored: 
- What factors were critical for the success of individual faculty members and for the success of the department and how could these factors be addressed?

- Was the cognitive mapping process helpful to the faculty member participating in an individual mapping session?

- Was the cognitive mapping process insightful to the faculty member participating in an individual mapping session?

- Was modeling a way that CIS faculty could reach a consensus on controversial and/or complex issues?

- Did each faculty member who participated in a cognitive mapping session agree with the resulting model?

- Did each faculty member who participated in a cognitive mapping session consider the resulting model accurate and complete?

Sixteen of the 33 faculty members in the department, or $48.5 \%$ of the faculty, volunteered to be interviewed, which is considered an adequate number of interviews to gather representative information. Eden and Ackermann (1998) conduct up to 20 individual interviews in organizations that are often very large. Individual CIS faculty members were interviewed to create cognitive maps representing what they believed was required for each participant to achieve his or her individual goals and for the department to achieve its strategic goals.

To capture sensitive information, the map of each faculty member remained confidential, and concepts and links were combined in a composite map that was made public, as recommended by Eden and Ackermann (1998). Data collected for this paper include individual maps and questionnaires filled out by faculty at the end of each mapping session. Questionnaire items appear together with responses in the results and discussion sections. These maps were then used in planning the faculty retreat during which the departmental strategy was to be formulated.

\subsection{Individual and composite maps}

Both authors of this paper were faculty members in the CIS department described in this paper. A total of 16 faculty members were interviewed by one author and one undergraduate student to create the individual maps. One of the authors was trained by Ackermann, the expert in formulating strategy through cognitive mapping using the Decision Explorer ${ }^{\mathrm{TM}}$ software (Eden and Ackermann 1998) and assisted in a one-day session facilitated by Ackermann. With four years of experience in planning for and using cognitive mapping, this researcher trained the second author and the two students for a month and was present to assist the novice facilitators during initial cognitive mapping sessions. Maps were elicited with one of the authors serving as the facilitator or observer for each mapping session.

Although a one-hour interview session was scheduled for each faculty member, some interviews lasted up to one-and-a-half hours. Each facilitator interviewed and created the cognitive map for approximately four faculty members. The facilitator repeated the three main questions at the beginning of each mapping session. Each facilitator used techniques described in Eden and Ackermann (1998) to create cognitive maps and to prompt each 


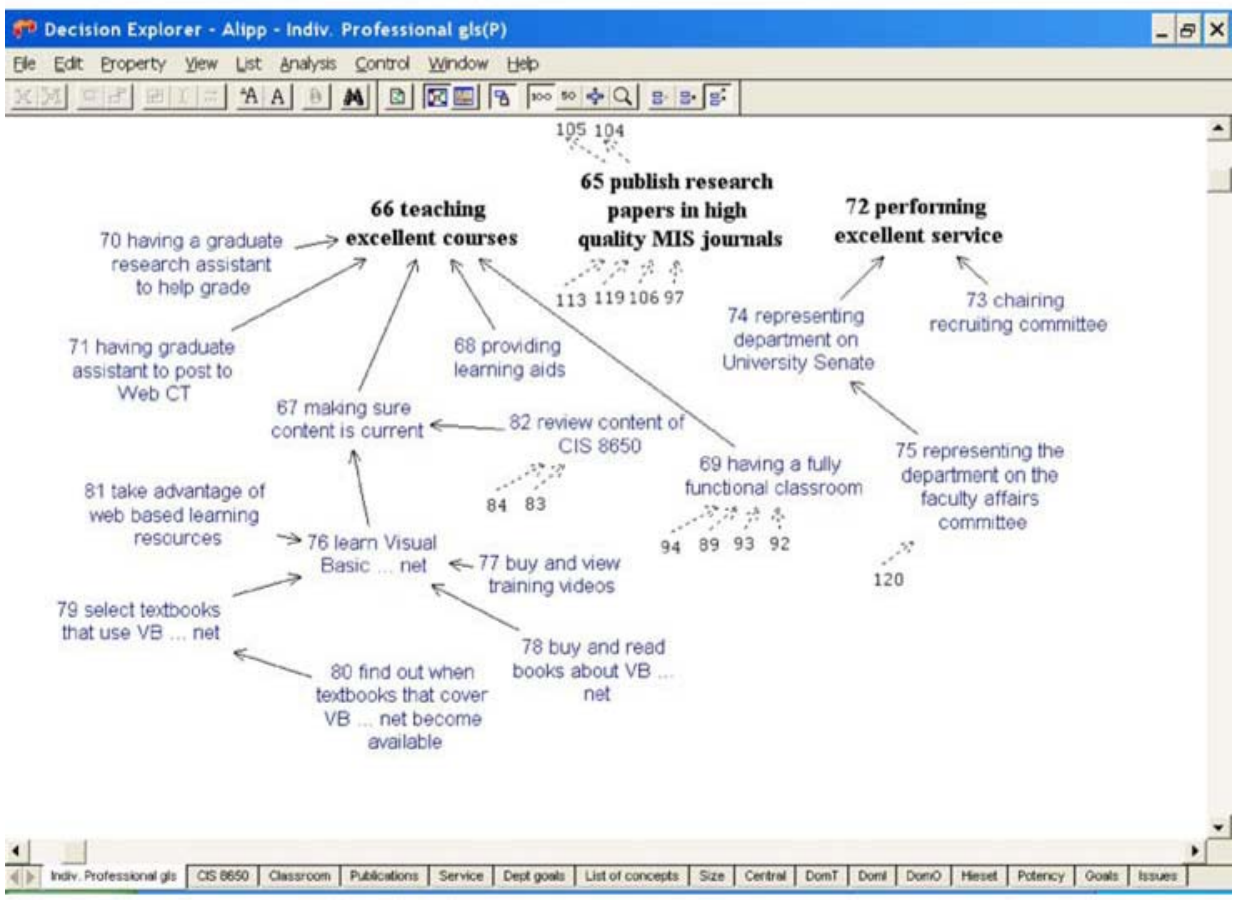

igure 2. Cognitive map representing the views of a faculty member.

interviewee to ladder up (asking “Why?”) and to ladder down (asking “How?”). Individual mapping sessions were scheduled over a three-month period. The strategic plan was to be formulated during a retreat attended by the entire faculty one year after individual mapping began.

\section{Results}

The cognitive mapping process used by Eden and Ackermann (1998) involves identifying concepts, which are usually verb phrases of up to 14 words, and causal links that are read as “may lead to.” Figure 2 shows one view (screen) of a Decision Explorer ${ }^{\mathrm{TM}}$ model generated during one individual mapping session. Permission to use the map was obtained from the faculty member. The purpose of creating individual cognitive maps was to elicit and represent the thinking of each individual by adopting a future-oriented approach in the wording ofcon-cepts (as verb phrases) and in determining causal connections between concepts. Concepts in black font were identified by the faculty member being interviewed as goals. Numbers uniquely identify each concept and the order in which the faculty member expressed them. Goals (in bold, black font) indicate major desired outcomes while solid lines and arrowheads identify the linkage and causal direction. Dotted lines and arrowheads show links to concepts and causality directions associated with other screens of the same individual's map. 
Table 1. Responses to individual mapping sessions.

\begin{tabular}{lrrr}
\hline Question $(n=15)$ & Yes & No & Not sure \\
\hline Did you find the cognitive mapping process helpful? & 11 & $1^{*}$ & 4 \\
Did you find the cognitive mapping process insightful? & 12 & 1 & 2 \\
Is modeling a way that CIS faculty can reach a consensus on controversial and/or & 4 & 3 & 8 \\
$\quad$ complex issues? & 15 & 0 & 0 \\
Do you agree with the resulting model? & 14 & 0 & 1 \\
Is the model accurate? & 7 & 2 & 4 \\
Is the model complete? & & 4
\end{tabular}

*Onc person chccked both Yes and No and said "Not helpful for personal goals [but] helpful for dcpartmcntal goals."

To encourage honest input from faculty, facilitators explained that individual maps would not be shared with anyone other than the facilitators. Not only were concepts from individual maps combined in a single list and arranged in alphabetical order, but duplicate concepts were removed; as a result, it was impossible for anyone to reconstruct any individual maps based on the list of all combined concepts. A composite map, which was the congregate of inputs from individual maps, was created by one of the authors and made available to faculty electronically. Two views (screens) of this larger map are shown in Figures 3 and 4. Concepts 148, 168, and 187, which appear in a larger font in Figure 3, were identified as critical issues that need to be addressed, while 139 was identified as the composite goal.

\subsection{Summary of survey responses}

Of the 16 faculty members who participated in the individual mapping sessions, 15 completed and submitted paper-pencil questionnaires. An overwhelming majority of the participating faculty (69\%) felt that the process was helpful and insightful (Table 1). Similarly, all of the participants agreed with the causal representations of the resulting individual model, and all but one felt that the model created during an individual mapping session was accurate. However, few participants (27\%) felt that modeling was a way for CIS faculty to reach a consensus on controversial and/or complex issues. Opinion was divided about whether the model resulting from a single mapping session was complete, with $50 \%$ agreeing that the model from their mapping session was complete.

A summary of the comments related to the questions is presented in Table 2. Positive, negative, and neutral comments are grouped together, as are comments expressing concerns about the process.

\subsection{Success factors identified}

Factors that faculty identified as being important to their own success or to the success of the department are listed in Table 3. These concepts, which are listed without regard to 


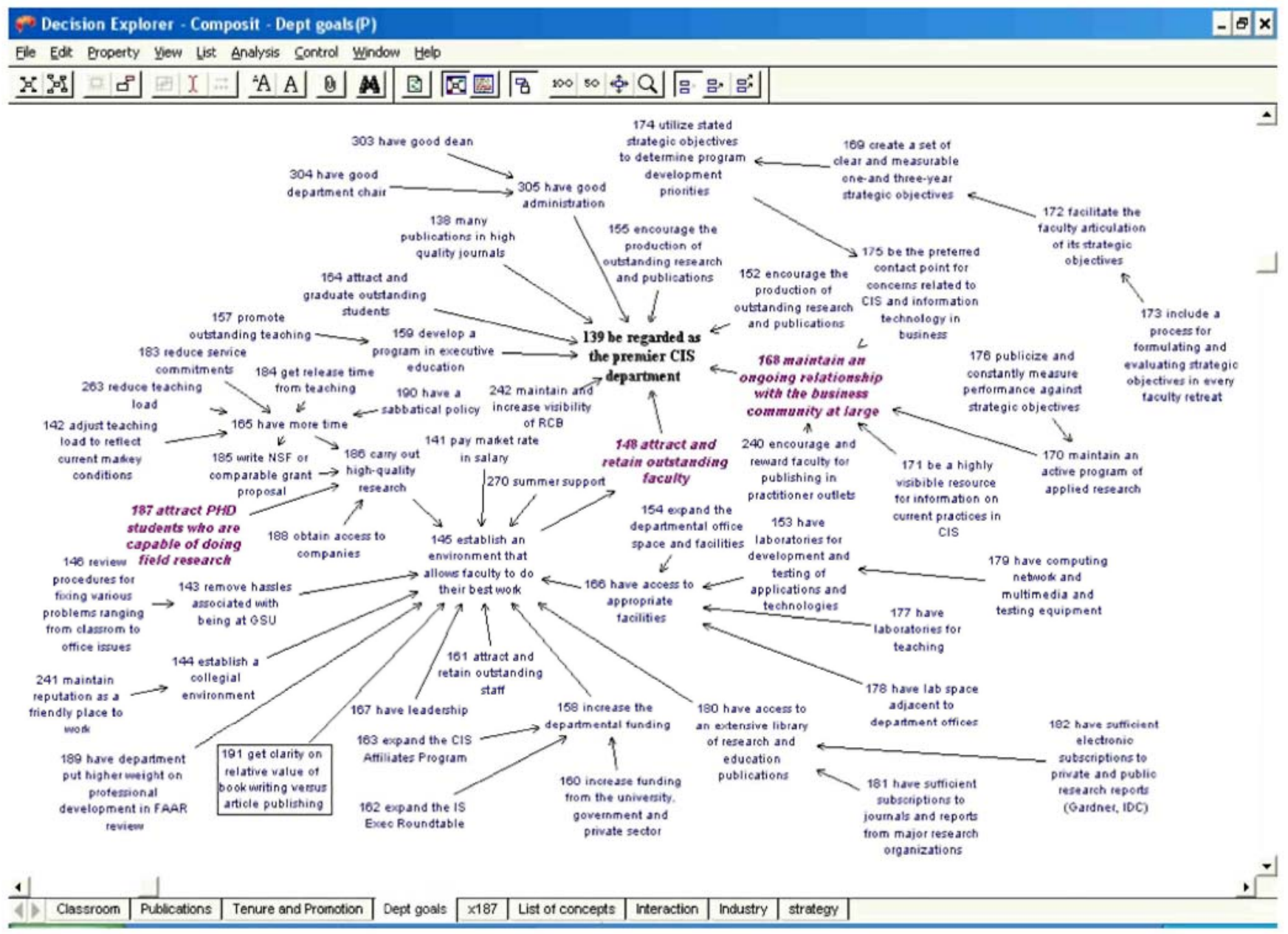

Fïgure 3. Composite of individual maps. 


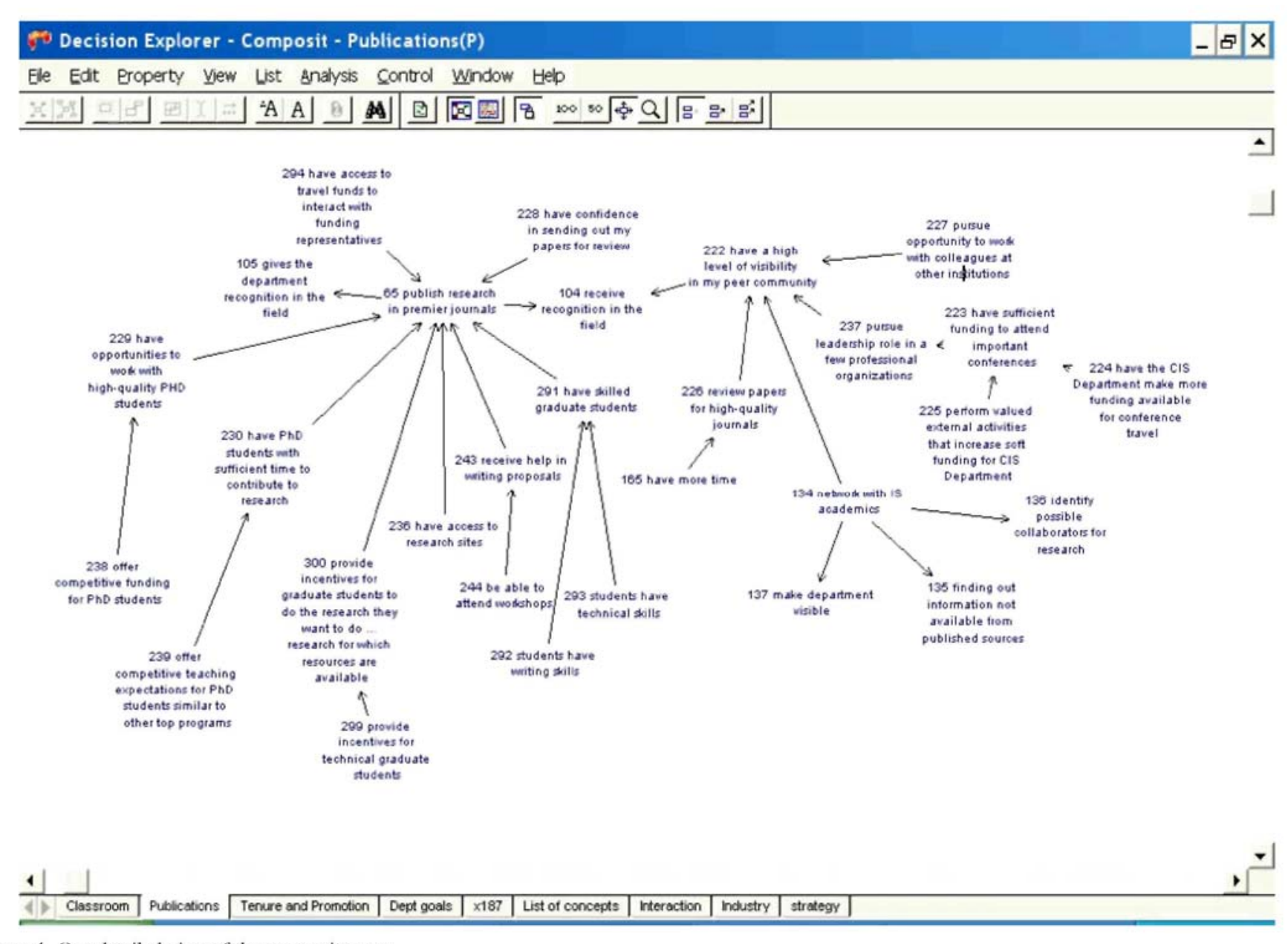

Figure 4. One detailed view of the composite map. 
Table 2. Comments in response to survey questions.

\begin{tabular}{|c|c|}
\hline Question & Responses \\
\hline Did you find the cognitive mapping process helpful? & $\begin{array}{l}\text { "Forced me to be complete in my thinking" } \\
\text { "Helped to clarify means-end relationships" } \\
\text { "Not helpful for personal goals/ Helpful for } \\
\text { departmental goals" } \\
\text { "I reserve judgment until I see how it all comes together" }\end{array}$ \\
\hline Did you find the cognitive mapping process insightful? & $\begin{array}{l}\text { "Allowed me to think about linkages" } \\
\text { "Interconnectivity of goal interesting. . but no surprises," } \\
\text { "It translated insights into causal map. It may remove } \\
\text { some insights too, but I can't think of an example." }\end{array}$ \\
\hline $\begin{array}{l}\text { Is modeling a way that CIS faculty can reach a } \\
\text { consensus on controversial and/or complex issues? }\end{array}$ & $\begin{array}{l}\text { "I'm not sure. If people disagree on controversial issues, } \\
\text { then they will disagree on the map also. At best it } \\
\text { will help people who disagree to find some common } \\
\text { areas of agreement." } \\
\text { "Consensus may never be achievable but the process } \\
\text { may create better understanding" } \\
\text { "Mapping seems more useful for identification of issues } \\
\text { rather than consensus formulation." }\end{array}$ \\
\hline $\begin{array}{l}\text { How valuable and/or useful do you feel that the map } \\
\text { we produced today will be for the CIS department? }\end{array}$ & $\begin{array}{l}\text { "Very useful because I believe it will overlap with the } \\
\text { others' maps" } \\
\text { "Valuable. I like this tool." } \\
\text { "Very helpful in getting all views - not just a few" } \\
\text { "It's tough to say - if all of the maps are edited (by } \\
\text { [facilitator] and [facilitator]) and combined, there's } \\
\text { good potential." } \\
\text { "Potential for being honest \& open, but I fear it will lead } \\
\text { nowhere" } \\
\text { "Moderate. These will be use[d] to justify decisions that } \\
\text { have already been made" }\end{array}$ \\
\hline $\begin{array}{l}\text { Do you agree with the resulting model? Is the model } \\
\text { accurate? Is the model complete? }\end{array}$ & $\begin{array}{l}\text { "reasonably" } \\
\text { "Pretty much," } \\
\text { "But it is w/r to the domain of concern" } \\
\text { "More time needed - could go on for days" } \\
\text { "Few things (concepts) missing b/c we ran out of time. } \\
\text { They've got the important concepts - peripheral." }\end{array}$ \\
\hline $\begin{array}{l}\text { What would you change about the strategic planning } \\
\text { process next time? }\end{array}$ & $\begin{array}{l}\text { "Nothing." [4 respondents] } \\
\text { "Bigger screen/ less editing - go back \& fix minor typos } \\
\text { later." } \\
\text { "Have the entire faculty participate in a session" } \\
\text { "Emphasize anonymity and how this will be used." } \\
\text { "Longer time. More intervention. More like action } \\
\text { research or facilitation." }\end{array}$ \\
\hline
\end{tabular}




\begin{tabular}{ll}
\hline Question & Responses \\
\hline $\begin{array}{l}\text { How was the mapping process different from your } \\
\text { writing a memo or report? }\end{array}$ & $\begin{array}{c}\text { "Graphical - better way to represent interdependence of } \\
\text { activities" } \\
\text { "Relationships [are] more clearly identified" } \\
\text { "It focused first on high level issues rather than on the } \\
\text { detailed issues." } \\
\text { "Allows for more spontaneous development of ideas, } \\
\text { issues, \& objectives." } \\
\text { "Not a substitute for [a] memo or report, but certainly a } \\
\text { catalyst for them." } \\
\text { "More novel. It helped but it leaves out a lot of } \\
\text { qualifications and detail." } \\
\text { "Anonymity" [2 people] } \\
\text { "private, non judgmental, unfiltered" } \\
\text { "Graphical, intensive, more personal, richer } \\
\text { representation of my thinking" } \\
\text { "Superior to attempting to capture it in linear text" } \\
\text { "More thought [about] interrelationships of goals/issues" } \\
\text { "Provides for an iterative process" } \\
\text { "Took more time. Does not provoke a response from } \\
\text { others." }\end{array}$ \\
\hline
\end{tabular}

any time sequence or degree of importance, are visible in the composite map presented earlier (Figure 4).

\subsection{Moving to the strategic plan}

As mentioned above, individual maps were never shared. However, a list of concepts, with duplicates removed, was disseminated via e-mail to the faculty for discussion. After considerable debate on possible retreat formats, the committee charged with planning the retreat decided to have faculty read and discuss two case studies and engage in role playing, so that success factors identified during individual mapping sessions could be explored. A committee member who had written many business case studies wrote a new case describing the department's situation.

A composite map showing success factors generated from individual maps was made available to the committee by the authors, and these success factors were incorporated into the case describing the department, as well as the scenarios for role playing. Faculty members assumed the roles of faculty members of various ranks and specialties and engaged in discussions with others who played the role of the department chair. The use of cognitive mapping described in this paper proved to be very successful in surfacing success factors. 
Table 3. Success factors identified.

Success factors for individual faculty

- Have access to travel funds to interact with funding representatives

- Have Ph.D. students with sufficient time to contribute to research

- Receive skilled graduate assistant

- Receive help in writing proposals

- Have sufficient funding to attend important conferences

- Have access to research sites

- Be able to receive training in the classes that I am expected to teach

- Attract Ph.D. students who are capable of doing morale field research

- Attract people (Ph.D. students) with prior work experience in a business environment

- Have access to appropriate facilities

- Have access to an extensive library of research and education publications
Success factors for the department

- Attract and retain outstanding faculty

- Maintain an ongoing relationship with the business community at large

- Establish a collegial environment

- Have good administration

- Attract and retain outstanding staff

- Attract and retain outstanding graduate students increase the departmental funding

- Have a high level of

- Raise external funding

- Fund Ph.D. students with competitive stipends

- teaching excellent courses

- recognize and respect differences in research paradigms

- create a set of clear and measurable 1-year and 3year strategic objectives

\section{Discussion}

\subsection{Quality of facilitation}

During the first cognitive mapping sessions facilitated by novice facilitators as part of the initial training, the experienced facilitator who was observing the session suggested a few additional questions. In later sessions, the observing facilitator concluded that all appropriate questions had been asked. Responses to questionnaire items confirm the impressions of the most experienced facilitator (Table 1) that there was consistency in the quality of facilitation. All 15 faculty members agreed with the resulting model. Fourteen faculty members agreed that the resulting model was accurate, while one person was not sure. Responses to the question of whether the resulting model was complete were divided. Seven faculty members felt that the map was complete, while two did not, and four were not sure. Although the same novice facilitator, who was a student, served as the facilitator during the two sessions for which the faculty member felt that the map was not complete, in one case the senior faculty member commented: "More time needed - could go on for days." In the other case, the faculty member commented: "More focus at the start." No association between the facilitator involved and 'Not Sure' answers to the question of whether the map was complete could be found. Every facilitator was involved in at least one facilitation session 
after which the faculty member being interviewed was uncertain about whether the map was incomplete.

Instead of using paper and pencil to create individual cognitive maps as suggested by Eden and Ackermann (1998), all maps associated with this study were created electronically using Decision Explorer ${ }^{\mathrm{TM}}$ during the mapping sessions. As a result, facilitators could edit concepts and links without dealing with a physical eraser, move concepts and links around on the screen without having to anticipate which areas on the map would become busy, create and link multiple views, use color and font size coding to identify goal(s) and key issues, avoid idiosyncrasies of facilitators' handwriting, and produce printouts of the map for later review and correction by faculty members. No research was undertaken to compare the speed and effectiveness of mapping using paper and pencil as opposed to mapping electronically. The authors felt that they and the students would be better able to manage maps produced using Decision Explorer ${ }^{\mathrm{TM}}$, and that the faculty being mapped would be better able to read the maps produced. Since all 16 faculty mapped were CIS faculty, it was unlikely that the people being mapped might be intimidated by working with a computerbased program, as occurred in the U.K. (Eden and Ackermann 1998). Maps ranged in size from 20 to 85 concepts and 19 to 78 links per map. Results of the study showed that most faculty found cognitive mapping using Decision Explorer $^{\mathrm{TM}}$ in individual interviews to be helpful and insightful for identifying core issues and solutions.

This study revealed that creating maps with Decision Explorer ${ }^{\mathrm{TM}}$ during individual mapping sessions using the methodology described above has the following advantages:

- Facilitators start with a blank slate, except for the framing questions. As a result, each faculty member focuses on only those topics of interest to him or her.

- Individuals being mapped determine the structure of the map. As a result, the bottom-up (faculty, as opposed to administration) approach can be effectively implemented.

- Both faculty and facilitators have a visual presentation, which helps both identify gaps in the model (missing concepts, explanations, and consequences).

- Maps are complete when the mapping sessions end. There is no possibility of having errors introduced when the facilitator enters the concepts and links from a paper-andpencil map into Decision Explorer. ${ }^{\mathrm{TM}}$

One challenge of using Decision Explorer ${ }^{\mathrm{TM}}$ in cognitive mapping was that it required the facilitator to have cognitive mapping facilitation skills as well as the ability to work effectively and efficiently. Mapping online, a supposed tousing pencil and paper, requires the facilitator to be very familiar with the software. The cognitive map produced using Decision Explorer ${ }^{\mathrm{TM}}$ was the only record of the mapping session. For this reason, familiarity with the software and cognitive mapping facilitation skills are crucial in using Decision Explorer $^{\mathrm{TM}}$ effectively in the mapping process.

Both authors were aware that their being members of the department meant that they were not disinterested parties, as hired consultants would be. Constructing maps by laddering up and laddering down made it relatively easy for the authors to avoid introducing personal biases because each individual map served as a point of reference for follow-up questions. The authors feel that the facilitators were trusted to protect the confidentiality of faculty 
members, since some maps expressed views that faculty members would not have shared if they had been identified.

The authors would have preferred to conduct the entire strategic planning process in a shorter time frame, as Eden and Ackermann (1998) recommend. However, only the schedule for the individual mapping sessions was under their control. Individual mapping sessions took place over three months in the summer and fall. As is often the case in academic departments, faculty became busy with their day-to-day responsibilities during the academic year and would not have been receptive to having still another activity forced into their schedules. The retreat took place at the end of the same academic year, when the department chair felt that teaching and other responsibilities were winding down.

\section{Conclusion}

Most faculty members felt that the cognitive mapping process, which involved creating a map directly in Decision Explorer ${ }^{\mathrm{TM}}$, helped them identify their own as well as departmental success factors. Similarly, most faculty members found the process insightful. By creating individual maps, individual faculty members were able to confidentially articulate their goals, which issues the department should address, and how these issues should be addressed. The resulting individual maps provided a detailed representation of each faculty member's thinking that showed causal relationships between goals, issues, and actions.

According to the department head, use of individual interviews and cognitive mapping to surface goals, problems, and possible solutions led to "greater and deeper participation by the faculty" in the strategic planning process. He commented: "I thought the engagement inhabited the data I saw. Greater and deeper participation not only should improve the resulting strategic plan, but also commitment to the plan.”

Using Decision Explorer ${ }^{\mathrm{TM}}$ in capturing the faculty member's thoughts during each cognitive mapping session enabled the faculty to detect missing information and causal links as well as to confirm the accuracy of the concepts and links displayed. However, when cognitive mapping is used, interviewers must have special training in cognitive mapping facilitation. Mapping directly into Decision Explorer ${ }^{\mathrm{TM}}$ during an interview also requires skill in using the software.

\section{References}

Ackermann, F. and C. Eden. (2004). “Using Causal Mapping: Individual and Group, Traditional and New,” in: Pidd, M. (ed.), Systems Modeling: Theory and Practice. Chichester: Wiley, pp. 127-145. 
Ackermann, F., C. Eden, and I. Brown. (2005). The Practice of Making Strategy: A Step-by-Step Guide. London: Sage.

Ackermann, F., C. Eden, and T. Williams. (1997). "Modeling for Litigation: Mixing Qualitative and Quantitative Approaches," Interfaces 27, 48-65.

Alavi, M., G. M. Marakas, and Y. Yoo. (2002). "A Comparative Study of Distributed Learning Environments,” Information Systems Research 13(4), 404-415.

Bougon, M. G. (1992). “Congregate Cognitive Maps: A Unified Dynamic Theory of Organization and Strategy,” Journal of Management Studies 29(3), 369-389.

Braa, K. and R. Vidgen. (1999). "Interpretation, Intervention, and Reduction in the organizational Laboratory: a Framework for In-Context Information System Research,” Accounting, Management and Information Technologies 9, 25-47.

Brown, S. M. (1992). “Cognitive Mapping and Repertory Grids for Qualitative Survey Research: Some Comparative Observations,” Journal of Management Studies 29(3), 287-308.

Bryson, J. M. (1995). Strategic Planning for Public and Nonprofit Organizations. San Francisco: Jossey-Bass.

Bryson, J., F. Ackermann, C. Eden, and C. Finn. (1995). "Using the "Oval Mapping Process” to identify Strategic Issues and Formulate Effective Strategies,” in: Bryson, J. M. (ed.), Strategic Planning for Public and Nonprofit Organizations. San Francisco: Jossey-Bass.

Bryson, J.,F.Ackermann, C. Eden, and C. Finn. (2004). Visible Thinking: Unlocking Causal Mapping for Practical Business Results. Chichester: Wiley.

Checkland, P. (1991). "From Framework Through Experience to Learning: The Essential nature of Action Research,” in: Nissen H.-E., Klein H. K., and Hirschheim R. (eds.), Information systems Research: Contemporary Approaches and Emergent Traditions. Amsterdam: Elsevier.

Decision Explorer ${ }^{\mathrm{TM}}$ Reference Manual, Version 3.1. (2000). Glasgow: Banxia Software Limited.

Decision Explorer ${ }^{\mathrm{TM}}$ User's Guide, Version 3. (1997). Glasgow: Banxia Software Limited.

Dennis, A. R., C. K. Tyran, D. R. Vogel, and J. F. Jr. Nunamaker. (1997). "Group support systems for strategic planning,” Journal of Management Information Systems 14(1), 155-184.

Eden, C. (2004). “Analyzing Cognitive Maps to Help Structure Issues or Problems,” European Journal of Operational Research 159(3), 673-686.

Eden, C. and F. Ackermann. (1998). Making Strategy: The Journey of Strategic Management. London: Sage.

Eden, C. and F. Ackermann. (2001). “Contrasting Single User and Networked Group Decision Support Systems for Strategy Making,” Group Decision and Negotiation 10(1), 47-66.

Eden, C. and F. Ackermann. (2001). “Group Decision and Negotiation in Strategy Making,” Group Decision and Negotiation 10(2), 119-140.

Glew, D. J., A. M. O’Leary-Kelly, and D. D. Van Fleet. (1995). "Participation in Organizations: A preview of the Issues and Proposed Framework for Future Analysis,” Journal of Management 21(3), 395-421.

Hodgkinson, G. P., A. J. Maule, and N. J. Bown. (2004). “Causal Cognitive Mapping in the Organizational Strategy Field: A Comparison of Alternative Elicitation Procedures,” Organizational Research Methods 7(1), 3-26.

Huff, A. S. (ed.) (1990). Mapping Strategic Thought. New York: Wiley.

Kim, W. C. and R. Mauborgne. (1998). "Procedural Justice, Strategic Decision Making, and the Knowledge Economy,” Strategic Management Journal 19(4), 323-338.

Laukkanen, M. (1998). “Conducting Causal Mapping Research: Opportunities and Challenges,” in: Eden C. and Spender J.-C. S. (eds.) Managerial and Organizational Cognition. London: Sage.

Lipp, A. and C. Y. Carver. (2000). "Using Web Groupware and Cognitive Mapping in a CIS Department to Review and Revise the Assessment Process and Document Reasoning,” in: Proceedings of the Thirty-Third Annual Hawaii International Conference on System Sciences, IEEE Computer Society Press, 1-10.

Morton, A., F. Ackermann, and V. Belton. (2003). “Technology-Driven and Model-Driven Approaches to Group Decision Support: Focus, Research Philosophy, and Key Concepts,” European Journal of Information Systems 12, 110-26.

Mosvick, R. and R. Nelson. (1987). We 've Got to Start Meeting Like This: A Guide to Successful Business Meeting Management. Glenview, IL: Scott, Foresman.

Narayanan, V. K. and D. J. Armstrong. (2005). Causal Mapping for Research in Information Technology. Hershey, PA: Idea Group Publishing. 
Nelson, K.M.,S. Nadkarni, V. K. Narayanan, and M.Ghods. (2000). “Understanding Software Operations Support Expertise: A Revealed Causal Mapping Approach,” MIS Quarterly 23(3), 475-507. Power, D. J. (1988).

“Anticipating Organization Structures”, in J. Hage ed., Futures of Organizations: Innovating

to Adapt Strategy and Human Resources to Rapid Technological Change. Lexington, Massachusetts: Lexington Books. Sheetz, S. D., G. Irwin, D. P. Tegarden, H. J. Nelson, and D. E. Monarchi. (1997). “Exploring the Difficulties of

Learning Object-Oriented Techniques,” Journal of Management Information Systems 14(2), 103-131. Sheetz,

S. D., D. P. Tegarden, K. A. Kozar, and I. Zigurs. (1994). “A Group Support Systems Approach to Cognitive

Mapping,” Journal of Management Information Systems 11(1), 31-57. Susman, G. (1983). “Action Research:

A Sociotechnical System Perspective,” in G. Morgan ed., Beyond method:

Strategies for Social Research. Newbury Park, CA: Sage. Thompson, M. A. (2000). The Relationship

Between Organizational Learning Cultures and Participation in

Decision Making, Ph.D. dissertation, Georgia State University. Warren, K. (1995). "Exploring Competitive Futures Using Cognitive Mapping,” Long Range Planning 28(5),

10-21. 